\title{
The Role of Adipokines in Understanding the Associations between Obesity and Depression
}

\author{
Valerie H. Taylor ${ }^{1}$ and Glenda M. MacQueen ${ }^{2}$ \\ ${ }^{1}$ Mood Disorders Program, Centre for Mountain Health Services, McMaster University, D150-A, 100 West 5th Street, \\ St. Joseph's Healthcare, Hamilton, ON, Canada L8N 3K7 \\ ${ }^{2}$ University of Calgary, 2500 University Drive Northwest Calgary, Calgary, AB, Canada T2N 1N4
}

Correspondence should be addressed to Valerie H. Taylor, taylorv@mcmaster.ca

Received 2 November 2009; Revised 26 May 2010; Accepted 16 June 2010

Academic Editor: Gianluca Iacobellis

Copyright ( 2010 V. H. Taylor and G. M. MacQueen. This is an open access article distributed under the Creative Commons Attribution License, which permits unrestricted use, distribution, and reproduction in any medium, provided the original work is properly cited.

\begin{abstract}
Objective. Two major causes of disability, major depression and obesity, share overlapping psychosocial and pathophysiological etiologies. Studies are now focused on biological mechanisms linking the two illnesses, and there is interest in the role that adipokines may have in mediating the association between obesity and depression. We reviewed the literature to look at what is currently known about this association, focusing on the adipokines leptin, adiponectin, and resistin. Methods. A MEDLINE search, citing articles from 1966 onward, supplemented by a review of bibliographies, was conducted to identify relevant studies. Results. This paper identified plausible pathways underlying a link between adipokines and depression. Only a few studies have yet been conducted specifically examining these biomarkers in patients with depression, but the results are intriguing. Conclusion. This paper is one of the first to examine the association between adipokines and depression. It provides an overview of the physiological role of adipokines and summarizes the data suggesting that they may be dysregulated in major depression. This area of research may become increasingly important as new treatment strategies are developed.
\end{abstract}

\section{Introduction}

Obesity elevates the risk of developing a number of diseases, including atherosclerosis, diabetes, nonalcoholic fatty liver disease, certain cancers, and immune-mediated disorders such as asthma [1-3]. There is also converging evidence that negative mood states and stress create susceptibility to physical illnesses such as the common cold and cardiovascular disease, resulting in premature mortality [46]. Underlying mechanisms such as chronic inflammation have been extensively investigated as candidate pathways that subsequently link obesity and depression in an attempt to explain how each confers vulnerability to the other and subsequently elevate as the risk for physical illness [7]. Other potential mediators of the obesity-depression association, such as changes in adipokines, however, have not yet been well explored.

Adipose tissue is no longer considered an inert tissue devoted to energy storage, and is now recognized as an endocrine organ capable of secreting a variety of biologically active components [8]. These secretory products called "adipokines" include leptin, resistin, and adiponectin. A number of these biomarkers are now being explored as a means of explaining the link between obesity and depression, and as a consequence, representing possible novel targets in the treatment of mental illness $[9,10]$. The primary object of this paper was to review the literature regarding the association between adipokines and major depressive disorder (MDD). This novel area of investigation may lead to new discoveries that help us understand depression and obesity, conditions that represent the largest psychological and physical causes of disability worldwide, respectively.

\section{Methods}

MEDLINE and PubMed searches were conducted of Englishlanguage articles published between 1950 and May 2010 using the following search terms: major depressive disorder, depression, cross-referenced with adipocytokine, adipokine, 
leptin, resistin, and adiponectin. In addition, reference lists from the identified publications were then manually reviewed. The search was conducted most recently on May 20, 2010.

\section{Evidence for an Association between Adiopokines and Depression Leptin}

3.1. An Overview of the Role of Leptin. Most of the evidence to date linking adipokines and MDD is focused on leptin. Leptin is produced primarily by differentiated adipocytes and exerts its influence on the central nervous system (CNS), suppressing food intake and stimulating energy expenditure [11]. It was initially identified as an antiobesity hormone, acting as a negative feedback adiposity signal to control energy homeostasis by interacting with its receptors in the hypothalamus [12]. Under conditions of regular eating cycles, leptin levels exponentially reflect the proportion of adipose tissue [13], and the most important variable that determines leptin concentration is body fat mass [14]. As a consequence of its role in satiety, leptin was initially thought to have an application in obesity treatment, but conversely, obese individuals often have increased leptin concentrations [15]. The high leptin levels associated with obesity are thought to be caused by leptin resistance, much as high insulin levels in type 2 diabetic patients are a consequence of resistance to insulin. Leptin resistance may occur at several levels, including impaired transport of leptin across the blood brain barrier, reduced function of the leptin receptor, and defects in leptin signal transduction $[16,17]$.

3.2. The Role of Leptin in Depression. The role of leptin in the pathophsiology of psychiatric disorders in general, and in depression in particular, is being explored. Leptin insufficiency and/or leptin resistance may contribute to vulnerability to depression [9]. Rats exposed to chronic stress have decreased levels of leptin and a variety of depressivelike behaviors have been reduced by leptin administration $[18,19]$. The data on the role of leptin in humans is more equivocal, however, and studies have reported increased [20, $21]$, decreased [22, 23], or unchanged [24] levels in people with depression.

3.3. Mechanisms of a Leptin-Depression Association. Along with its more clearly understood roles in energy metabolism, leptin also plays a role in the bidirectional communication between the hypothalamic pituitary adrenal (HPA) axis and the adipose system; however, the relationship between these systems have not been defined and most likely involve unknown factors. Leptin expression is also stimulated by glucocorticoids [25] but chronic or high intensity stress offsets this stimulatory effect and causes a reduction in leptin levels [26]. There is also a link between leptin and inflammation. Leptin is involved in modulating the immune response and increases the production of proinflammatory cytokines such as tumor necrosis-factor-alpha (TNF-a) and interleukin-6 (IL-6) [27]. Given that MDD is considered to be a proinflammatory state [7] and that dysregulation of the
HPA axis represents the most common biological alteration found in depression [28], while further work is required to characterize the neural circuits and signal transduction pathways that mediate leptin's action, there may be a potential role for this hormone both to explain some of the metabolic abnormalities associated with depression and as a trait marker of MDD itself.

\section{Adiponectin}

4.1. An Overview of the Role of Adiponectin. Adiponectin is primarily an adipocyte secretory protein involved in glucose and lipid homeostasis [29], but it is also expressed by skeletal muscle cells, cardiac myocytes, and endothelial cells [3032]. A negative correlation between obesity and circulating adiponectin has been well established, and serum levels of adiponectin are markedly decreased in individuals with visceral obesity and states of insulin resistance, such as nonalcoholic fatty liver disease, atherosclerosis, and type 2 diabetes mellitus [33]. Adiponectin also has been increasingly linked to mood states and may be of particular interest to explain how stress arousal may impact psychiatric disease risk.

4.2. The Role of Adiponectin in Depression. The first epidemiological studies documenting an association between low levels of adiponectin and an increased risk of MDD were published in $2006[34,35]$. Since that time, adiponectin has become the most abundant adipose-derived plasma protein with antiinflammatory qualities observed to be associated with MDD [35, 36]. Circulating adiponectin levels have also been shown to correlate inversely with anxiety scores, a condition highly comorbid with depression [37].

Adiponectin has been suggested as a mediating factor in the association between obesity and psychopathology, and the adiponectin hypothesis stipulates that the link between the two conditions is directly related to hypoadiponectinemia [36]. The results of studies examining adiponectin in clinical populations have been variable, however. While the original work in this area reported a decrease in plasma adiponectin concentrations in symptomatic patients with MDD [35] and an increase in adiponectin in patients with depression that was successfully treated [34], other studies have been unable to find changes in people with depression $[10,38,39]$. This effect may be mediated by antidepressants in the short-term [40] and weight gain over time [41], but recent work suggests that the presence of weight gain and depression also appears to be additive. The two conditions appear to have a greater effect on adiponectin that either does separately [42], indicating that an underlying vulnerability may be conferred and then compounded by either of the two conditions and their resultant hypoadiponectinemia.

4.3. Mechanisms of an Adiponectin-Depression Association. Adiponectin regulates the expression of several pro- and antiinflammatory cytokines and has been shown to both reduce secretion and attenuate the biological effects of TNF-a [43-45] and to induce the production of antiinflammatory cytokines such as interleukin-10 (IL-10) and 
interleukin-1 receptor antagonist (IL-1RA) [46]. Expression of adiponectin is also regulated by proinflammatory mediators such as IL-6, which have been shown suppress adiponectin transcription and translation [47]. Weight loss is a potent inducer of adiponectin synthesis [48] and the decreased synthesis of adiponectin, apparent in individuals who are obese, might lead to dysregulation of the controls that inhibit the production of proinflammatory cytokines, thereby leading to the production of increased levels of proinflammatory mediators. The HPA axis also plays a role in adiponectin regulation; adiponectin gene expression is reversibly downregulated by dexamethasone [49], and glucocorticoids have been shown to inhibit adiponectin function [50].

Interpretation of the role of adiponectin in depression is complicated by potential confounding variables such as weight, other cardiovascular risk factors, medical comorbidities, and the role of pharmacotherapy, but its role is worth exploring. The links between adiponectin, inflammation, and HPA axis dysregulation highlight a biologically plausible mechanism linking it to MDD.

\section{Resistin}

5.1. An Overview of the Role of Resistin. Resistin is produced by adipocytes, macrophages, myocytes, and pancreatic cells [51], but its physiological role in humans is still uncertain [52]. Initial animal studies suggested that obesity induced by a high-fat diet or mutation of the leptin gene or receptor is associated with increased circulating resistin concentrations $[53,54]$. Other groups, however, have observed opposite results [55], showing that resistin expression was downregulated in rodent models of diet-induced obesity [56-58] and suppressed by free fatty acids [59]. The proinflammatory properties of resistin do suggest that it has a role in inflammatory processes, however [60], and it is likely involved in the chronic inflammatory reactions associated with obesity $[58,61,62]$.

5.2. The Role of Resistin in Depression. As the role of resistin in inflammation and obesity has not been defined, there is limited information to ascertain whether it contributes to the increased risk of physical illness in people with MDD. Only 3 studies have examined this adipokine as it relates to depression, and of these, the results are variable. One study found both an association between free cortisol and resistin in patients with depression [10] and a subsequent decrease in resistin when patients were successfully treated that was not seen in medication nonresponders, while a separate study in Chinese patients found no link between the two [39]. A third study recently found a positive correlation between resistin levels and depression [42], but in this case the increase was for atypical, but not typical depressive symptoms only. These findings support previous biological data on differences between atypical and melancholic features subtypes of MDD [63] and are consistent with the negative results of the investigation reporting no association between resistin and typical depressive symptoms [39].
5.3. Mechanisms of a Resistin-Depression Association. While much is left to learn about the role of resistin, what we do know does support the possibility of an association between resistin and depression. Resistin has been reported to inhibit dopamine and noradrenaline release in the hypothalamus [64] and, thus, through its contribution to decreased intrasynaptic monoamine levels, it could also predispose to depressive symptomatology. It also has links to inflammation and the HPA axis, and further work is required to investigate its role in MDD.

\section{The Role of Cortisol as a Mediator between Adipokines, Obesity, and Depression}

Cortisol is proposed as a pathophysiological mediator in excess weight gain and recent reports have suggested that a state of primary intracellular cortisol excess may exist in obesity. This pseudohypercortisolism could be a result of increased activity of $11 \beta$-hydroxysteroid dehydrogenase1 (11 $\beta$-HSD-1), the enzyme that reduces cortisone to cortisol and is capable of elevating intracellular cortisol levels in adipose tissue cells [65]. Interest in a link between cortisol and MDD was initially stimulated by work with Cushing's disease, an illness characterized by cortisol excess secondary to either endogenous hyperactivation of the HPA axis or treatment with corticosteroids. The typical physical phenotype of central obesity that accompanies this neuroendrocrine dysregulation is often accompanied by an alteration in mood that interestingly can be successfully treated by removal of the pituitary or adrenal tumors or by corticosteroid production inhibitors, rather than by use of classical antidepressants [66].

The association between MDD and cortisol may be accounted for in part by exposure to stress; chronic stress leads to cortisol elevation and both retrospective and prospective studies suggest that major psychological stressors both precede the first episode of a mood disorder [67] and are related to relapse [68]. As a consequence of elevated stress, a cascade of events occurs in the HPA axis beginning with increased release of corticotrophin releasing hormone $(\mathrm{CRH})$ and arginine vasopressin (AVP) from the paraventricular nucleus (PVN) of the hypothalamus. CRH and AVP subsequently stimulate the release of adrenocorticotropic hormone (ACTH) from the pituitary, which travels via the peripheral circulation to the adrenals and enhances the secretion of cortisol. Cortisol functions as a feedback regulator of the HPA axis, acting via glucocorticoid receptors (GR) in the hypothalamus, pituitary, and other brain regions. A significant subset of depressed persons show: (1) elevations in the 24-h excretion of cortisol in the urine; (2) elevations in plasma cortisol and ACTH; (3) elevations in cerebrospinal fluid levels of CRH; (4) failure of feedback inhibition of cortisol secretion by the cortisol analog dexamethasone; and (5) a blunted ACTH but normal cortisol secretion to exogenously administered CRH (reviewed in [69]). The resolution of all previously dysregulated HPA axis parameters including hypercortisolemia, blunted ACTH response to $\mathrm{CRH}$, hypesecretion of $\mathrm{CRH}$, 
and adrenal hypertrophy following successful antidepressant treatment provides independent support for the involvement of the HPA axis in depression [69-71]. All of the adipokines reviewed above regulate HPA function in some way, and all therefore have potential to impact circulating cortisol levels.

\section{Summary}

The secretory function of adipocytes has established adipose tissue as an endocrine organ. Obesity is not only accompanied by inflammation [72], but is also associated with altered levels of the adipokines, favoring an increase in leptin and resistin, a decrease in adiponectin, and alterations in levels of cortisol. The changes in these biomarkers are more difficult to quantify in patients with MDD but an emerging body of evidence suggests that further investigation is warranted to describe the links between obesity, depression, and adiokine levels.

Current mechanisms to explain the interrelationships between depression and adiposity using structured equation modeling hypothesized that depression promotes weight accumulation, causing an inflammatory response, which in turn entails either an expanded adipose tissue release of IL-6 or a leptin-induced upregulation of IL-6 release by white blood cells [73]. This explanation, while biologically plausible, does not include the role of cortisol and more recent data on an expanding role of adipokines in linking stress and weight gain to inflammation and disease.

While work in this area needs to be done in order to identify the cause and effect of these different contributors, there does appear to be evidence that would support exploring this area further.

\section{References}

[1] K. E. Wellen and G. S. Hotamisligil, "Inflammation, stress, and diabetes," Journal of Clinical Investigation, vol. 115, no. 5, pp. 1111-1119, 2005.

[2] E. E. Calle and R. Kaaks, "Overweight, obesity and cancer: epidemiological evidence and proposed mechanisms," Nature Reviews Cancer, vol. 4, no. 8, pp. 579-591, 2004.

[3] D. M. Mannino, J. Mott, J. M. Ferdinands et al., "Boys with high body masses have an increased risk of developing asthma: findings from the National Longitudinal Survey of Youth (NLSY)," International Journal of Obesity, vol. 30, no. 1, pp. 6-13, 2006.

[4] B. H. Brummett, J. C. Barefoot, I. C. Siegler et al., "Characteristics of socially isolated patients with coronary artery disease who are at elevated risk for mortality," Psychosomatic Medicine, vol. 63, no. 2, pp. 267-272, 2001.

[5] S. Cohen, D. A. J. Tyrrell, and A. P. Smith, "Psychological stress and susceptibility to the common cold," The New England Journal of Medicine, vol. 325, no. 9, pp. 606-612, 1991.

[6] S. Stewart-Brown, "Emotional wellbeing and its relation to health," British Medical Journal, vol. 317, no. 7173, pp. 16081609, 1998.

[7] B. I. Goldstein, D. E. Kemp, J. K. Soczynska, and R. S. McIntyre, "Inflammation and the phenomenology, pathophysiology, comorbidity, and treatment of bipolar disorder: a systematic review of the literature," The Journal of Clinical Psychiatry, vol. 70, no. 8, pp. 1078-1090, 2009.

[8] S. Galic, J. S. Oakhill, and G. R. Steinberg, "Adipose tissue as an endocrine organ," Molecular and Cellular Endocrinology, vol. 316, no. 2, pp. 129-136, 2009.

[9] X.-Y. Lu, “The leptin hypothesis of depression: a potential link between mood disorders and obesity?" Current Opinion in Pharmacology, vol. 7, no. 6, pp. 648-652, 2007.

[10] B. Weber-Hamann, J. Kratzsch, D. Kopf et al., "Resistin and adiponectin in major depression: the association with free cortisol and effects of antidepressant treatment," Journal of Psychiatric Research, vol. 41, no. 3-4, pp. 344-350, 2007.

[11] H. Munzberg, "Leptin-signaling pathways and leptin resistance," Forum of Nutrition, vol. 63, pp. 123-132, 2010.

[12] J. K. Elmquist, C. Bjørbæk, R. S. Ahima, J. S. Flier, and C. B. Saper, "Distributions of leptin receptor mRNA isoforms in the rat brain," Journal of Comparative Neurology, vol. 395, no. 4, pp. 535-547, 1998.

[13] K. N. Frayn, F. Karpe, B. A. Fielding, I. A. Macdonald, and S. W. Coppack, "Integrative physiology of human adipose tissue," International Journal of Obesity, vol. 27, no. 8, pp. 875$888,2003$.

[14] J. R. Speakman, R. J. Stubbs, and J. G. Mercer, "Does body mass play a role in the regulation of food intake?" Proceedings of the Nutrition Society, vol. 61, no. 4, pp. 473-487, 2002.

[15] M. Rosická, M. Kršek, M. Matoulek et al., "Serum ghrelin levels in obese patients: the relationship to serum leptin levels and soluble leptin receptors levels," Physiological Research, vol. 52, no. 1, pp. 61-66, 2003.

[16] H. Münzberg and M. G. Myers Jr., "Molecular and anatomical determinants of central leptin resistance," Nature Neuroscience, vol. 8, no. 5, pp. 566-570, 2005.

[17] K. El-Haschimi, D. D. Pierroz, S. M. Hileman, C. Bjørbæk, and J. S. Flier, "Two defects contribute to hypothalamic leptin resistance in mice with diet-induced obesity," Journal of Clinical Investigation, vol. 105, no. 12, pp. 1827-1832, 2000.

[18] X.-Y. Lu, C. S. Kim, A. Fraser, and W. Zhang, "Leptin: a potential novel antidepressant," Proceedings of the National Academy of Sciences of the United States of America, vol. 103, no. 5, pp. 1593-1598, 2006.

[19] C. S. Kim, T. Y. Huang, J. Garza, et al., "Leptin induces antidepressant-like behavioral effects and activates specific signal transduction pathways in the hippocampus and amygdala of mice," Neuropsychopharmacology, vol. 31, pp. S237-S238, 2006.

[20] I. A. Antonijevic, H. Murck, R.-M. Frieboes, R. Horn, G. Brabant, and A. Steiger, "Elevated nocturnal profiles of serum leptin in patients with depression," Journal of Psychiatric Research, vol. 32, no. 6, pp. 403-410, 1998.

[21] R. T. Rubin, M. E. Rhodes, and R. K. Czambel, "Sexual diergism of baseline plasma leptin and leptin suppression by arginine vasopressin in major depressives and matched controls," Psychiatry Research, vol. 113, no. 3, pp. 255-268, 2002.

[22] G.-M. Jow, T.-T. Yang, and C.-L. Chen, "Leptin and cholesterol levels are low in major depressive disorder, but high in schizophrenia," Journal of Affective Disorders, vol. 90, no. 1, pp. 21-27, 2006.

[23] T. Kraus, M. Haack, A. Schuld, D. Hinze-Selch, and T. Pollmächer, "Low leptin levels but normal body mass indices in patients with depression or schizophrenia," Neuroendocrinology, vol. 73, no. 4, pp. 243-247, 2001. 
[24] M. Deuschle, W. F. Blum, P. Englaro et al., "Plasma leptin in depressed patients and healthy controls," Hormone and Metabolic Research, vol. 28, no. 12, pp. 714-717, 1996.

[25] M. A. Cimmino, G. Andraghetti, L. Briatore et al., "Changes in adiponectin and leptin concentrations during glucocorticoid treatment: a pilot study in patients with polymyalgia rheumatica," Annals of the New York Academy of Sciences, vol. 1193, pp. 160-163, 2010.

[26] D. A. Sandoval and S. N. Davis, "Leptin: metabolic control and regulation," Journal of Diabetes and Its Complications, vol. 17, no. 2, pp. 108-113, 2003.

[27] S. E. Wozniak, L. L. Gee, M. S. Wachtel, and E. E. Frezza, "Adipose tissue: the new endocrine organ? a review article," Digestive Diseases and Sciences, vol. 54, no. 9, pp. 1847-1856, 2009.

[28] S. R. Bornstein, A. Schuppenies, M.-L. Wong, and J. Licinio, "Approaching the shared biology of obesity and depression: the stress axis as the locus of gene-environment interactions," Molecular Psychiatry, vol. 11, no. 10, pp. 892-902, 2006.

[29] A. H. Berg, T. P. Combs, and P. E. Scherer, "ACRP30/adiponectin: an adipokine regulating glucose and lipid metabolism," Trends in Endocrinology and Metabolism, vol. 13, no. 2, pp. 84-89, 2002.

[30] R. Piñeiro, M. J. Iglesias, R. Gallego et al., "Adiponectin is synthesized and secreted by human and murine cardiomyocytes," FEBS Letters, vol. 579, no. 23, pp. 5163-5169, 2005.

[31] A. M. Delaigle, J.-C. Jonas, I. B. Bauche, O. Cornu, and S. M. Brichard, "Induction of adiponectin in skeletal muscle by inflammatory cytokines: in vivo and in vitro studies," Endocrinology, vol. 145, no. 12, pp. 5589-5597, 2004.

[32] A. M. Wolf, D. Wolf, M. A. Avila et al., "Up-regulation of the anti-inflammatory adipokine adiponectin in acute liver failure in mice," Journal of Hepatology, vol. 44, no. 3, pp. 537-543, 2006.

[33] Y. Arita, S. Kihara, N. Ouchi et al., "Paradoxical decrease of an adipose-specific protein, adiponectin, in obesity," Biochemical and Biophysical Research Communications, vol. 257, no. 1, pp. 79-83, 1999.

[34] K. Narita, T. Murata, T. Takahashi, H. Kosaka, N. Omata, and Y. Wada, "Plasma levels of adiponectin and tumor necrosis factor-alpha in patients with remitted major depression receiving long-term maintenance antidepressant therapy," Progress in Neuro-Psychopharmacology and Biological Psychiatry, vol. 30, no. 6, pp. 1159-1162, 2006.

[35] R. Leo, G. Di Lorenzo, M. Tesauro et al., "Decreased plasma adiponectin concentration in major depression," Neuroscience Letters, vol. 407, no. 3, pp. 211-213, 2006.

[36] Y. Yilmaz, "Psychopathology in the context of obesity: the adiponectin hypothesis," Medical Hypotheses, vol. 70, no. 4, pp. 902-903, 2008.

[37] T. Nagata and H. Yamada, "Psycho-neuro-immunological aspects of eating disorders," International Congress Series, vol. 1287, pp. 279-284, 2006.

[38] G. Mamalakis, M. Kiriakakis, G. Tsibinos et al., "Depression and serum adiponectin and adipose omega-3 and omega6 fatty acids in adolescents," Pharmacology Biochemistry and Behavior, vol. 85, no. 2, pp. 474-479, 2006.

[39] A. Pan, X. Ye, O. H. Fanco et al., "The association of depressive symptoms with inflammatory factors and adipokines in middle-aged and older Chinese," PLoS ONE, vol. 3, no. 1, article e1392, 2008.
[40] Y.-C. Chen, W.-W. Lin, Y.-J. Chen, W.-C. Mao, and Y.J. Hung, "Antidepressant effects on insulin sensitivity and proinflammatory cytokines in the depressed males," Mediators of Inflammation, vol. 2010, Article ID 573594, 7 pages, 2010.

[41] T. You, B. J. Nicklas, J. Ding et al., "The metabolic syndrome is associated with circulating adipokines in older adults across a wide range of adiposity," Journals of Gerontology Series A, vol. 63, no. 4, pp. 414-419, 2008.

[42] S. Zeugmann, A. Quante, I. Heuser, R. Schwarzer, and I. Anghelescu, "Inflammatory biomarkers in 70 depressed inpatients with and without the metabolic syndrome," Journal of Clinical Psychiatry. In press.

[43] J. M. Fernández-Real, A. López-Bermejo, R. Casamitjana, and W. Ricart, "Novel interactions of adiponectin with the endocrine system and inflammatory parameters," Journal of Clinical Endocrinology \& Metabolism, vol. 88, no. 6, pp. 27142718, 2003.

[44] W. Aldhahi and O. Hamdy, "Adipokines, inflammation, and the endothelium in diabetes," Current Diabetes Reports, vol. 3 , no. 4, pp. 293-298, 2003.

[45] N. Ouchi, S. Kihara, T. Funahashi, Y. Matsuzawa, and K. Walsh, "Obesity, adiponectin and vascular inflammatory disease," Current Opinion in Lipidology, vol. 14, no. 6, pp. 561566, 2003.

[46] H. Tilg and A. M. Wolf, "Adiponectin: a key fat-derived molecule regulating inflammation," Expert Opinion on Therapeutic Targets, vol. 9, no. 2, pp. 245-251, 2005.

[47] M. Fasshauer, S. Kralisch, M. Klier et al., "Adiponectin gene expression and secretion is inhibited by interleukin-6 in 3T3-L1 adipocytes," Biochemical and Biophysical Research Communications, vol. 301, no. 4, pp. 1045-1050, 2003.

[48] J. M. Bruun, A. S. Lihn, C. Verdich et al., "Regulation of adiponectin by adipose tissue-derived cytokines: in vivo and in vitro investigations in humans," American Journal of Physiology, vol. 285, no. 3, pp. E527-E533, 2003.

[49] M. Fasshauer, J. Klein, S. Neumann, M. Eszlinger, and R. Paschke, "Hormonal regulation of adiponectin gene expression in 3T3-L1 adipocytes," Biochemical and Biophysical Research Communications, vol. 290, no. 3, pp. 1084-1089, 2002.

[50] F. Fallo, A. Scarda, N. Sonino et al., "Effect of glucocorticoids on adiponectin: a study in healthy subjects and in Cushing's syndrome," European Journal of Endocrinology, vol. 150, no. 3, pp. 339-344, 2004.

[51] I. N. Holcomb, R. C. Kabakoff, B. Chan et al., "FIZZ1, a novel cysteine-rich secreted protein associated with pulmonary inflammation, defines a new gene family," The EMBO Journal, vol. 19, no. 15, pp. 4046-4055, 2000.

[52] J. S. Flier, “The missing link with obesity?" Nature, vol. 409, no. 6818, pp. 292-293, 2001.

[53] O. Ukkola, "Resistin—a mediator of obesity-associated insulin resistance or an innocent bystander?" European Journal of Endocrinology, vol. 147, no. 5, pp. 571-574, 2002.

[54] A. R. Shuldiner, R. Yang, and D.-W. Gong, "Resistin, obesity, and insulin resistance - the emerging role of the adipocyte as an endocrine organ," The New England Journal of Medicine, vol. 345, no. 18, pp. 1345-1346, 2001.

[55] C. M. Steppan, S. T. Bailey, S. Bhat et al., "The hormone resistin links obesity to diabetes," Nature, vol. 409, no. 6818, pp. 307-312, 2001. 
[56] J. M. Way, C. Z. Görgün, Q. Tong et al., "Adipose tissue resistin expression is severely suppressed in obesity and stimulated by peroxisome proliferator-activated receptor $\gamma$ agonists," Journal of Biological Chemistry, vol. 276, no. 28, pp. 25651-25653, 2001.

[57] G. Milan, M. Granzotto, A. Scarda et al., "Resistin and adiponectin expression in visceral fat of obese rats: effect of weight loss," Obesity Research, vol. 10, no. 11, pp. 1095-1103, 2002.

[58] M. W. Rajala, S. Obici, P. E. Scherer, and L. Rossetti, "Adiposederived resistin and gut-derived resistin-like molecule- $\beta$ selectively impair insulin action on glucose production," Journal of Clinical Investigation, vol. 111, no. 2, pp. 225-230, 2003.

[59] C.-C. Juan, L.-C. Au, V. S. Fang et al., "Suppressed gene expression of adipocyte resistin in an insulin-resistant rat model probably by elevated free fatty acids," Biochemical and Biophysical Research Communications, vol. 289, no. 5, pp. 1328-1333, 2001.

[60] C. M. Kusminski, P. G. McTernan, and S. Kumar, "Role of resistin in obesity, insulin resistance and type II diabetes," Clinical Science, vol. 109, no. 3, pp. 243-256, 2005.

[61] J. Gómez-Ambrosi and G. Frübeck, "Do resistin and resistinlike molecules also link obesity to inflammatory diseases?" Annals of Internal Medicine, vol. 135, no. 4, pp. 306-307, 2001.

[62] R. Rea and R. Donnelly, "Resistin: an adipocyte-derived hormone. Has it a role in diabetes and obesity," Diabetes, Obesity and Metabolism, vol. 6, no. 3, pp. 163-170, 2004.

[63] J. W. Stewart, P. J. McGrath, F. M. Quitkin, and D. F. Klein, "Atypical depression: current status and relevance to melancholia," Acta Psychiatrica Scandinavica. Supplementum, no. 433, pp. 58-71, 2007.

[64] L. Brunetti, G. Orlando, L. Recinella, B. Michelotto, C. Ferrante, and M. Vacca, "Resistin, but not adiponectin, inhibits dopamine and norepinephrine release in the hypothalamus," European Journal of Pharmacology, vol. 493, no. 1-3, pp. 4144, 2004.

[65] N. M. Morton, "Obesity and corticosteroids: $11 \beta$ hydroxysteroid type 1 as a cause and therapeutic target in metabolic disease," Molecular and Cellular Endocrinology, vol. 316, no. 2, pp. 154-164, 2009.

[66] N. Sonino and G. A. Fava, "Psychiatric disorders associated with Cushing's syndrome: epidemiology, pathophysiology and treatment," CNS Drugs, vol. 15, no. 5, pp. 361-373, 2001.

[67] C. L. Hammen, "Stress and the course of unipolar and bipolar disorders," in Does Stress Cause Psychiatric Illness? C. M. Mazure, Ed., vol. 56, pp. 87-110, American Psychiatric Press, Washington, DC, USA, 1995.

[68] B. S. McEwen, "Protection and damage from acute and chronic stress: allostasis and allostatic overload and relevance to the pathophysiology of psychiatric disorders," Annals of the New York Academy of Sciences, vol. 1032, pp. 1-7, 2004.

[69] C. F. Gillespie and C. B. Nemeroff, "Hypercortisolemia and depression," Psychosomatic Medicine, vol. 67, no. 1, pp. S26S28, 2005.

[70] J. D. Amsterdam, G. Maislin, A. Winokur, N. Berwish, M. Kling, and P. Gold, "The oCRH stimulation test before and after clinical recovery from depression," Journal of Affective Disorders, vol. 14, no. 3, pp. 213-222, 1988.

[71] C. B. Nemeroff, G. Bissette, H. Akil, and M. Fink, "Neuropeptide concentrations in the cerebrospinal fluid of depressed patients treated with electroconvulsive therapy. Corticotrophin-releasing factor, $\beta$-endorphin and somatostatin," The British Journal of Psychiatry, vol. 158, pp. 59-63, 1991.
[72] P. Trayhurn and I. S. Wood, "Adipokines: inflammation and the pleiotropic role of white adipose tissue," British Journal of Nutrition, vol. 92, no. 3, pp. 347-355, 2004.

[73] G. E. Miller, K. E. Freedland, R. M. Carney, C. A. Stetler, and W. A. Banks, "Pathways linking depression, adiposity, and inflammatory markers in healthy young adults," Brain, Behavior, and Immunity, vol. 17, no. 4, pp. 276-285, 2003. 


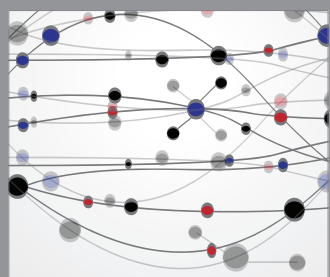

The Scientific World Journal
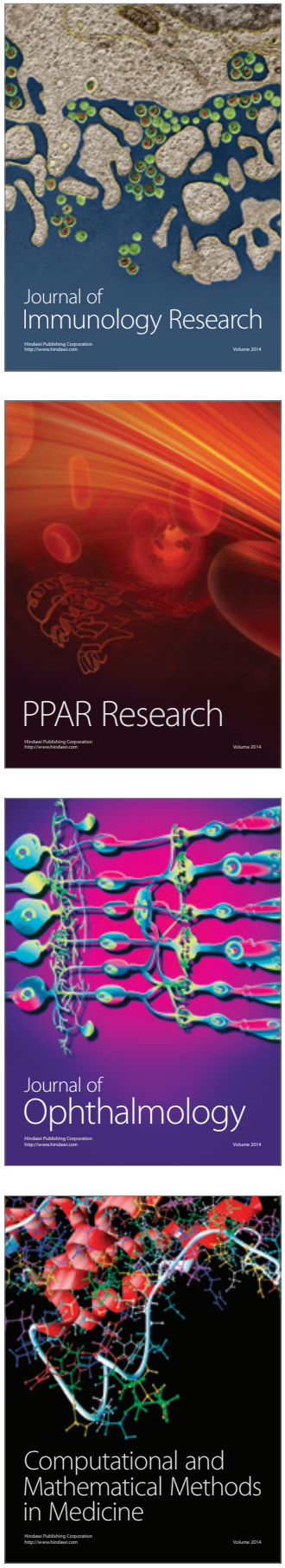

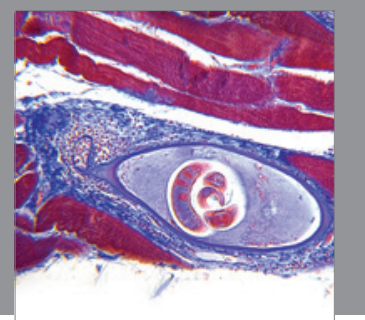

Gastroenterology

Research and Practice
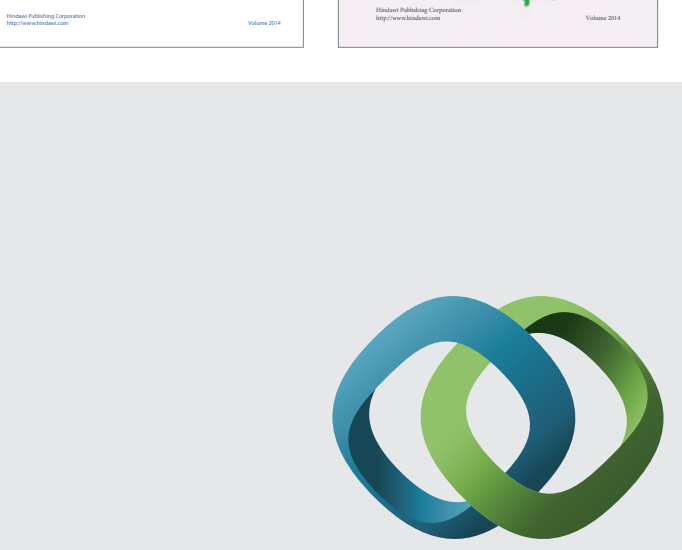

\section{Hindawi}

Submit your manuscripts at

http://www.hindawi.com
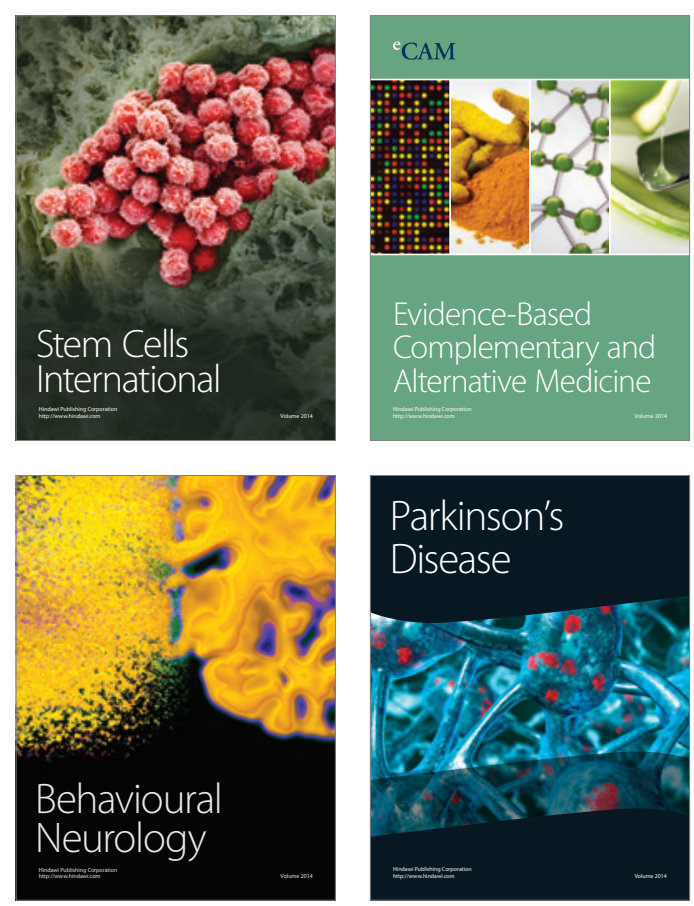

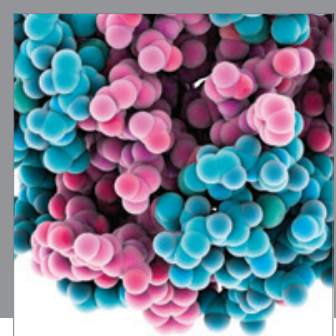

Journal of
Diabetes Research

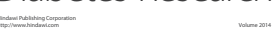

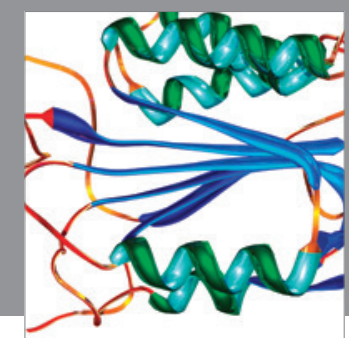

Disease Markers
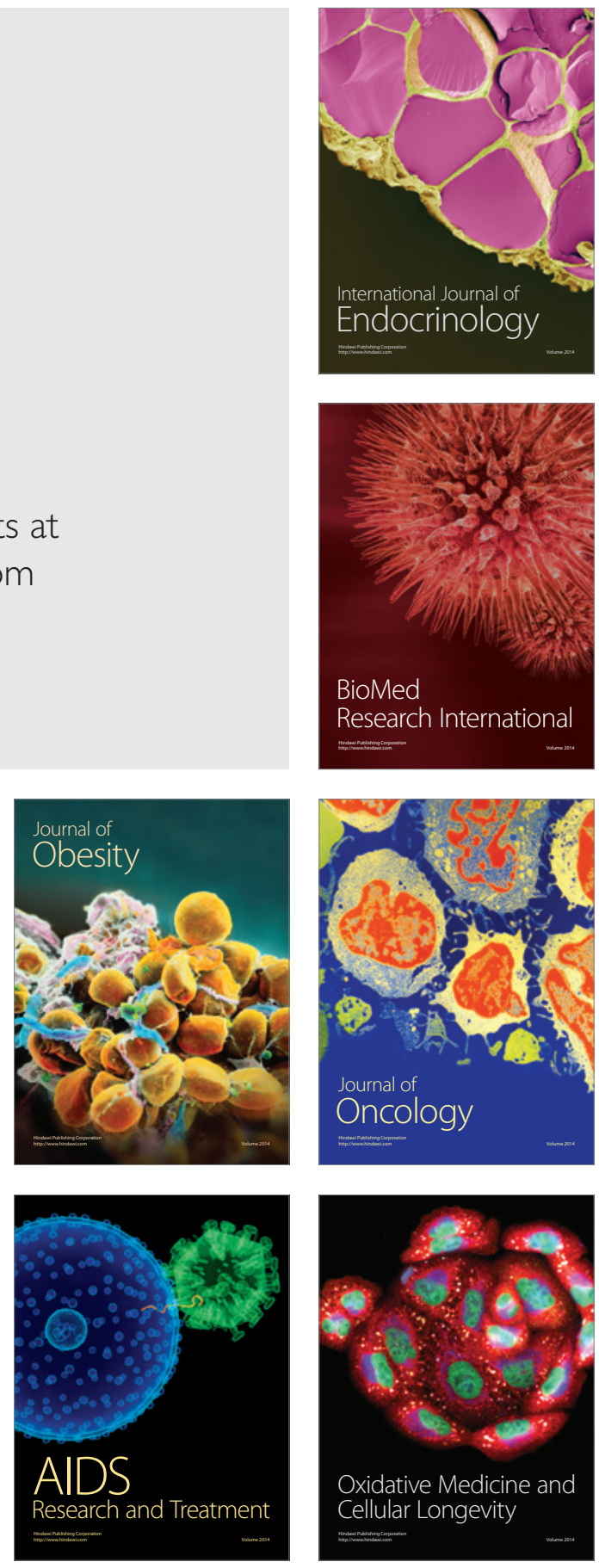